ISSN : 2550-0198

\title{
PEMERIKSAAN KESEHATAN MEDICAL CEK -UP SEDERHANA TEKANAN DARAH KADAR KOLESTEROL KADAR GULA DARAH DAN ASAM URAT PADA MASYARAKAT DI KEL. LABUHBARU BARAT KEC. PAYUNG SEKAKI KOTA PEKANBARU
}

\author{
Maswarni \\ Prodi D III Keperawatan, Fakultas MIPA dan Kesehatan \\ Universitas Muhammadiyah Riau \\ Email: maswarni82@yahoo.co.id
}

\begin{abstract}
Abstrak
Derajat kesehatan masyarakat suatu negara dipengaruhi oleh keberadaan sarana kesehatan. Sarana kesehatan yang diulas pada pada bagian ini berasal dari fasilitas pelayanan kesehatan yang terdiri dari : puskesmas, rumah sakit, dan Upaya Kesehatan Bersumberdaya Masyarakat (UKBM). Undang-Undang Nomor 36 tahun 2009 tentang Kesehatan menyatakan bahwa fasilitas pelayanan kesehatan adalah suatu alat dan/atau tempat yang digunakan untuk menyelenggarakan upaya pelayanan kesehatan, baik promotif, preventif, kuratif, maupun rehabilitatif yang dilakukan oleh pemerintah, pemerintah daerah, dan/atau masyarakat.Tujuan dari pelaksanakan pengabdian masyarakat ini adalah :Untuk memberikan Pelayanan Kepada Masyarakat kesehatan tentang Medikal Cek UpMempromosikan Program Studi D III Keperawatan Universitas Muhammadiyah Riau.Kegiatan ini dilakukan dengan metode pemeriksaan langsung pada peserta kegiatan dan edukasi mengenai hasil pemeriksaan. Pemeriksaan kadar kolesterol menggunakan alat autocheck dimana yang diukur adalah, tekanana darah, kadar kolesterol, kadar gula darah dan kadar asam urat .Kegiatan ini diselenggarakan pada hari rabu tanggal 09 A gustus 2017. Lokasi kegiatan dilakukan di Aula paguyuban Fajar Kota Pekanbaru. Jumlah peserta sebanyak 46 orang. Dari hasil pemeriksaan tekanan darah, didapatkan sebanyak sejumlah 27 orang (43\%) mengalami hipertensi, pada pemeriksaan gula darah terdapat 7 orang (15\%) mengalami peningkatan dari normal, pada kadar kolesterol terdapat 2 orang (4\%) yang mengalami hiperkolesterol sedangkan pada pemeriksaan Kadar asam urat terdapat 6 orang (13\%) mengalami kenaikan kadar asam urat sementara 11 orang (23\%) dalam kondisi normal
\end{abstract}

Kata kunci: Pemeriksaan ,kesehatan

\section{PENDAHULUAN}

Derajat kesehatan masyarakat suatu negara dipengaruhi oleh keberadaan sarana kesehatan. Sarana kesehatan yang diulas pada pada bagian ini berasal dari fasilitas pelayanan kesehatan yang terdiri dari : puskesmas, rumah sakit, dan Upaya
Kesehatan Bersumberdaya Masyarakat (UKBM). UndangUndang Nomor 36 tahun 2009 tentang Kesehatan menyatakan bahwa fasilitas pelayanan kesehatan adalah suatu alat dan/atau tempat yang digunakan untuk menyelenggarakan upaya pelayanan 
ISSN : 2550-0198

kesehatan, baik promotif, preventif, kuratif, maupun rehabilitatif yang dilakukan oleh pemerintah, pemerintah daerah, dan/atau masyarakat.

Tenaga kesehatan di Provinsi Riau tahun 2015 berjumlah 23.076 orang menurun dari tahun 2014 yang berjumlah 23199 orang. Penurunan jumlah tenaga kesehatan sebanyak $0,53 \%$ dan sangat berpengaruh terhadap peningkatan mutu pelayanan kesehatan yang semakin tinggi.

Tenaga kesehatan memiliki peranan penting untuk meningkatkan kualitas pelayanan kesehatan yang maksimal kepada masyarakat agar masyarakat mampu untuk meningkatkan kesadaran, kemauan, dan kemampuan hidup sehat sehingga akan terwujud derajat kesehatan yang setinggi-tingginya sebagai investasi bagi pembangunan sumber daya manusia yang produktif secara sosial dan ekonomi serta sebagai salah satu unsur kesejahteraan umum Tenaga kesehatan merupakan kunci utama dalam keberhasilan pencapaian tujuan pembangunan bidang kesehatan di Indonesia. Jumlah tenaga kesehatan diperlukan untuk mengetahui ketersediaan dan kekurangan tenaga kesehatan di Indonesia.

Berdasarkan Undang Undang Nomor 36 Tahun 2014 tentang Tenaga Kesehatan, tenaga kesehatan adalah setiap orang yang mengabdikan diri dalam bidang kesehatan serta memiliki pengetahuan dan/atau keterampilan melalui pendidikan di bidang kesehatan yang untuk jenis tertentu memerlukan kewenangan untuk melakukan upaya kesehatan.
Salah satu unsur yang berperan dalam percepatan pembangunan kesehatan adalah tenaga kesehatan yang bertugas di fasilitas pelayanan kesehatan di masyarakat. Berdasarkan data tahun 2015 jumlah tenaga medis (Dokter Spesialis, Dokter Umum, Dokter Gigi dan Dokter Gigi Spesialis) sebanyak 2.457 orang yang terdiri atas 2.063 tenaga Dokter Spesialis dan Dokter Umum serta 394 tenaga dokter gigi dan dokter gigi spesialis.

\section{METODE PELAKSANAAN}

Pengabdian ini dilakukan dengan cara memeriksa tekanan darah dan kadar kolesterol, kadar gula darah dan kadar Asam Urat dilanjutkan dengan konsultasi hasil secara bergilir. Masyarakat yang datang dicatat identitasnya (nama,umur, jenis kelamin) lalu dipersilahkan menuju meja pemeriksaan.

Masyarakat yang telah diperiksa tekanan darah dan kadar kolesterol, kadar gula darah dan kadar Asam Urat lalu diberikan kertas hasil pemeriksaan untuk konsultasi bersama pakar secara dua arah.

Kegiatan ini diselenggarakan pada hari Rabu, tanggal 09 Agustus 2017 Lokasi kegiatan dilakukan di Aula Paguyuban Fajar Ujung Kota Pekanbaru

\section{HASIL DAN PEMBAHASAN}

Kegiatan pengabdian pemeriksaan tekanan darah dan kadar kolesterol, kadar gula darah dan kadar Asam Urat konsultasi hasil telah dilakukan kepada 46 orang masyarakat Kel.Labuhbaru Barak Kec. Payung Sekaki. Peserta yang mengikuti kegiatan ini dapat diklasifikasikan 
ISSN : 2550-0198

dari usia dan jenis kelamin, yakni ada 31 orang perempuan dan 15 orang laki-laki. Rentang usia peserta yang mengikuti pengabdian ini adalah usia 30-70 tahun.

Tabel 2. Data peserta berdasarkan usia

\begin{tabular}{lc}
\hline Usia & Jumlah \\
\hline 20-30 tahun & 2 \\
31-40 tahun & 6 \\
41-50 tahun & 15 \\
51-60 tahun & 18 \\
$>60$ tahun & 5 \\
Total & 46 \\
\hline
\end{tabular}

\section{KESIMPULAN}

Skrining awal pemeriksaan tekanan darah dan kadar kolesterol, kadar gula darah dan kadar Asam Urat . Kegiatan ini diikuti 46 peserta, pemeriksaan tekanan darah, didapatkan sebanyak sejumlah 27 orang $(43 \%)$ mengalami hipertensi , pada pemeriksaan gula darah terdapat 7 orang $(15 \%)$ mengalami peningkatan dari normal, pada kadar kolesterol terdapat 2 orang (4\%) yang mengalami hiperkolesterol sedangkan pada pemeriksaan Kadar asam urat terdapat 6 orang $(13 \%)$ mengalami kenaikan kadar asam urat sementara 11 orang $(23 \%)$ dalam kondisi normal.

\section{UCAPAN TERIMAKASIH}

Terimakasih kepada Lembaga Penelitian dan Pengabdian Kepada Masyarakat yang telah memberikan dana untuk pelaksanaan kegiatan pengabdian ini. Terimakasih kepada masyarakat di Kelurahan Labuhbaru Kecamatan Payung Sekaki atas kerjasamanya sehingga pengabdian sukses dalam pelaksanaanya.

\section{DAFTAR PUSTAKA}

[1] Badan Pusat Statistik Kota Pekanbaru, (2010). Kecamatan Payung Sekaki Dalam Angka.http://www.riau24.com

[2] Badan Pusat Statistik Kota Pekanbaru, (2014). Kecamatan Payung Sekaki Dalam Angka.http://www.riau24.com

[3] Lestari, Dita D, Diana, Purwanto \& Stefana H. M. Kaligis. 2013. Gambaran Kadar Glukosa Darah Puasa pada Mahasiswa Angkatan 2011 Fakultas Kedokteran Universitas Samratulangi dengan Indeks Masa Tubuh $18,5-22,9 \mathrm{~kg} / \mathrm{m} 2$. Jurnal eBiomedik (eBM). Vol 1, No 2.

[4] Duyton, A.C, 1983, Buku Teks Fisiologi Kedokteran, edisi V, bagian 2, terjemahan Adji Dharma et al.,E.G.C., Jakarta.

[5] Tjokroprawiro, A, 1997, Hidup Sehat dan Bahagia Bersama Diabetes, Penerbit Gramedia Pustaka Utama, Jakarta.

[6] Ruhyanudin, Faqih. 2007. Asuhan Keperawatan Pada Klien Dengan Gangguan Sistem Kardiovaskular. Malang : Universitas Muhammadiyah Malang Press.

[7] Sadikin, M. 2001. Biokimia darah. Widya Medika.

[8] Soegondo, S. 2010. Diabetes Mellitus. http://www. medicastore.com.

[9] Susalit, E. Kapojos .E.J. Lubis .H.R. 2001. Ilmu Penyakit Dalam Jilid II. Edisi ke-3.

[10] FKUI : Jakarta Vitahealth. 2006. Asam Urat. Jakarta. PT Gramedia Pustaka Utama. 